\title{
Poética dos materiais na arquitetura contemporânea
}

\author{
Ricardo Nascimento FABBRINi \\ Professor do Departamento de FIlosofia da USP
}

Em Dentro do nevoeiro, Guilherme Wisnik articula de modo engenhoso reflexão estética e produção artística e arquitetônica contemporâneas. ${ }^{.}$É um livro sobre a relação entre estética e política a partir dos anos 1990, que transita pelo urbanismo, arquitetura, instalação, pintura ou fotografia. Conceitos da crítica das artes visuais são transpostos pelo autor, com desenvoltura, para os campos da arquitetura e do urbanismo. Em texto que alia informação histórica e reflexão teórica, há análises cuidadosas de obras, que são tomadas como sintomas das mudanças na lógica artístico-cultural do capitalismo nos últimos quarenta anos. ${ }^{2}$

Nos comentários às obras singulares, o autor investiga em que medida a arte e a arquitetura "ainda têm condições de promover a aparição do novo e do assombro num mundo em que tal poder parece ter sido capturado pela dimensão global do espetáculo midiático" e da tecnociência, "roubando da arte toda a prerrogativa da inovação". ${ }^{3}$ No centro do livro, há a convergência entre arte e arquitetura

${ }^{\mathrm{I}}$ WISNIK, Guilherme. Dentro do nevoeiro. São Paulo, Ubu/Fapesp, 2018, p. I5; 31-33; 174; cf. também do próprio autor \& Julio Mariutti o artigo "Minimalismo pop”. In: Espaço em obra: cidade, arte, arquitetura. São Paulo, Edições SESC-São Paulo, 2018, p. I72-173.

${ }^{2}$ Neste livro, o autor mobiliza tanto a crítica de arte e da arquitetura quanto a reflexão estética contemporânea de autores de diferentes extrações teóricas, tais como Walter Benjamin; Gilles Deleuze; Roland Barthes; Jean Baudrillard; Jean-François Lyotard; Nicolas Bourriaud; Fredric Jameson; Hal Foster; Georges Didi-Huberman; Slavoj Zizek.

${ }^{3}$ Ibid., p. 167. 
em uma poética dos materiais. ${ }^{4}$ Recorrendo ao ensaio "Transparência: literal e fenomenal" de Colin Rowe e Robert Slutzky, de 1963, que viam na transparência uma "conexão entre a poética plástica de pintores e de arquitetos”, Wisnik evidencia, por exemplo, as mudanças na arquitetura no tocante ao vidro. Da transparência, literal ou fenomênica, o autor desentranha simbolismos. Mostra o progressivo deslocamento do esqueleto estrutural calcado no ferro e na transparência do vidro da arquitetura racionalista do início do século XX, para os vidros com ornamentos historicistas da arquitetura dita pós-moderna dos anos 1980, e, destes, para os vidros espelhados da arquitetura corporativa como a dos centros financeiros nos anos 1990 e 2000; contra os quais se voltariam os vidros leitosos, que recusando o isolamento do edifício em relação ao entorno operariam como forma de resistência à arquitetura hegemônica. ${ }^{5}$

No imaginário dos pioneiros da arquitetura moderna, vale lembrar, o vidro simbolizava progresso tecnológico, igualdade democrática e transcendência utópica. Sua transparência ao permitir a integração entre espaço interno e espaço externo, teria rompido com o falseamento das fachadas ornadas que encobriam a vida de seu interior: "A modernidade [como sintetiza Wisnik a partir de Anthony Vidler] se erigiu, em suma, sobre o mito da transparência". ${ }^{6}$ Legatária do ethos

${ }^{4}$ Não se atém o livro ao debate sobre os termos moderno e pós-moderno. Próximo da periodização de Gilles Lipovetsky, Wisnik situa a dita arquitetura “pós-moderna” - que se seguiu ao fim do projeto moderno na arquitetura que remontava ao início do século XX - aos anos 1980, reservando o termo "arquitetura contemporânea” para designar a arquitetura depois do pós-moderno (dos anos 1990 aos anos 2000); ressaltando, evidentemente, a polêmica que envolve o termo "contemporâneo", como bem mostrou Giorgio Agamben: "o contemporâneo é aquele que não se deixa cegar pelas luzes de seu século, pois percebe o escuro do seu tempo como algo que lhe concerne e não cessa de interpelá-lo”. (AGAMBEN, Giorgio. O que é contemporâneo? e outros ensaios. Tradução de Vinicius Nicastro Honesko. Chapecó: Argos, 2009, p. 63; cf. também LIPOVETSKY, Gilles \& SEBASTIEN, Charles. Os tempos hipermodernos. Tradução de Mário Vitela. São Paulo, Barcarolla, 2004, p. 5I-IoI; e, por fim, WISNIK, Guilherme, op. cit., p. 30I). Sendo assim, mesmo não reconstituindo o debate, hoje já devidamente mapeado, sobre o suposto fim do projeto moderno, ou mesmo sobre a proclamada "morte da arte", ou ao menos de certa ideia de arte - a da arte moderna vinculada por artistas de vanguarda e críticos de arte do século XX, às noçóes de revolução e de utopia - o autor constrói, entre tantos aspectos, uma história de longa duração na arquitetura (do início do século passado ao início de nosso século) na perspectiva de uma poética dos materiais.

\footnotetext{
${ }^{5}$ Ibid., p. 277.

${ }^{6}$ Ibid., p. 7 .
} 
iluminista que informou a arte e a arquitetura modernas, a transparência do vidro foi tomada, portanto, como "índice de verdade, despojamento, honestidade e pureza" ${ }^{7}$ Assinale-se nesta direção, que o ideal de transparência materializada seja nas galerias, estaçôes de trem, nos pavilhões das exposições universais do fim do século XIX; seja nas obras de Paul Scheebart, Bruno Taut ou Walter Gropius (segundo Rowe e Slutzky), remontam à própria origem da filosofia ocidental - à democracia grega. ${ }^{8} \mathrm{O}$ valor da transparência literal compreendia assim, segundo o imaginário racionalista ocidental, um espaço comum e igualitário, simétrico e laicizado porque não mais confinado à meia-luz dos santuários; afinal tudo transcorria na democracia ateniense nos séculos $\mathrm{V}$ e IV a. C. à plena luz do dia: o cidadão que adentrava a ágora da polis, a tudo via enquanto por todos era visto; além do que, a manifestação de opiniốes; os debates travados, a elaboração das leis; assim como as decisões judiciais nelas baseadas, eram igualmente orientados pelo valor da transparência.

Esse ideal de vida social e política simbolizada pela transparência (ou pela ausência de ambiguidades) do vidro, que se tornou programático para os partidários da arquitetura funcionalista do início do século XX, foi, no entanto, alvo de críticas. Se o vidro é um "instrumento por excelência do esclarecimento racional moderno", ele "se apresenta historicamente como um inimigo tanto da propriedade quanto do mistério"; o que implica dizer que "por trás de sua superfície antiaurática, nada restaria escondido, em segredo".. Segundo Walter Benjamin, por exemplo, o vidro é um material asséptico e impessoal, "frio e sóbrio", que abole a memória e a experiência vivida. ${ }^{\mathrm{IO}}$ É um material "tão duro e tão liso" que nele "nada se fixa" o que significa dizer que ele não retém as marcas deixadas pela

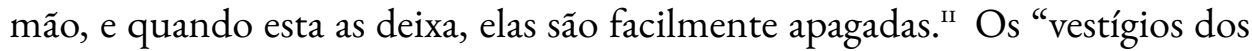
homens sobre a terra" teriam sido eliminados na "cultura de vidro" de Scheerbart,

7 Id.

${ }^{8}$ Ibid., p. 28. Cf. também os comentários do autor a Colin Rowe e Robert Slutzky, central em sua argumentação: “Transparency: Literal and Phenomenal”, Perspecta, n. 8, 1963, p. 167.

9 WISNIK, Guilherme. 20I8, p. 7.

Io BENJAMIN, Walter. "Experiência e pobreza”. In: Walter Benjamin, Magia e técnica, arte e politica: ensaios sobre literatura e história da cultura. 2ª edição. Obras escolhidas: v. I. São Paulo, Brasiliense, 1986, p. 117 .

${ }^{\text {II }}$ Id. 
ou no culto ao aço da Bauhaus, posto que "eles criaram espaços em que é difícil deixar rastros”, diz Benjamin. ${ }^{\text {I2 }}$

Dos vidros transparentes passou-se aos vidros espelhados. $\mathrm{Na}$ descrição do Hotel Bonaventure, em Los Angeles, de 1976, de John Portman, o crítico Fredric Jameson destacava os vidros espelhados que isolam o edifício de seu entorno, constituindo-se como um "espaço total, um mundo completo, uma espécie de cidade em miniatura". ${ }^{13}$ Enquanto a arquitetura de Le Corbusier abre-se à cidade, não no sentido de acolhê-la, mas no intento de transformá-la, ou seja, de difundir suas formas e modo de vida pela tessitura urbana, o Hotel Bonaventure de Portman teria voltado suas costas aos arredores. Se a primeira é autoconfiante e voluntariosa, apostando no poder social da forma-arquitetura funcional; a segunda seria narcisista uma vez que se mostra indiferente a tudo o que lhe é exterior. Somente dos elevadores panorâmicos situados nas quatro torres que ladeiam o átrio central do Hotel - com lagos em miniatura, boutiques e escadas rolantes, como em shopping centers ou parques de diversóes - é que o visitante pode ver a cidade, que acaba reduzida à mera imagem, a um skyline espectral. Se esta imagem fascina - ainda segundo Jameson - é porque ela decorreria da "paixão niilista pelos modos de desaparição do real”, na expressão de Baudrillard. ${ }^{14}$

Certa arquitetura contemporânea, no entanto, tem recusado tanto os vidros transparentes da arquitetura moderna (com seu simbolismo) quanto dos vidros espelhados da arquitetura corporativa da era global, em favor da "transparência fenomênica” dos vidros leitosos. Da translucidez deste vidro, situada entre o

${ }^{\mathrm{I} 2}$ Ibid., p. II8.

I3 JAMESON, F. Apud WISNIK, Guilherme, op. cit., p. 2or. Cf. também "Pósmodernismo e sociedade de consumo". In: JAMESON, Friedrich. A virada cultural. Rio de Janeiro, Civilização Brasileira, 2006, p. 17-44.

${ }^{14}$ BAUDRILLARD, Jean. Simulacros e simulação. Lisboa, Antropos, p. 197. Este cenário de puro artifício que é o átrio do Hotel Bonaventure, com suas superfícies brilhantes e espelhadas, desorienta de tal modo o corpo sensório-motor do visitante que este não consegue mais localizar-se em seu interior. Essa impossibilidade de mapeamento cognitivo do "hiperespaço" do Hotel -, que remete às noções de "não-lugar”, de Marc Augé, e de "junkspace”, de Rem Koolhaas, - vem se acentuando celeremente nas duas últimas décadas, como bem mostra o autor; basta observar "os aplicativos como o Google Maps e o Waze", que levam a "um rebaixamento [ainda maior] da nossa cognição do espaço”. (WISNIK, Guilherme, op. cit., p. 2oI) 
transparente e o espelhado, decorreria um efeito de nublamento. Seria "nas superfícies ambíguas dos vidros jateados”, nas “membranas estranhas” através das quais "as coisas [no interior ou no exterior do edifício] aparecem como espectros e sombras” que residiria a potência crítica da forma, na poética dos materiais de Wisnik. Is

É possível supor, estendendo a poética do autor, que na refração do feixe de luz que atravessa uma pele de vidro leitoso, ocorra um desvio (uma espécie de clinâmen, no termo de Lucrécio, ou de détournément minimun, na expressão de Guy Debord, Roland Barthes, ou Gilles Deleuze) que, velando ou distorcendo o que é visto, devolva a essa imagem, seu enigma. Esses "véus translúcidos que deixam entrever algo dos espaços interiores envolvendo-os em mistério" operariam, assim, a nosso ver, como forma de resistência às imagens hegemônicas da sociedade da hipervisibilidade: as imagens planas; chapadas; lisas; superficiais; epidérmicas; peliculares; sem recuo; sem enigma, sem face oculta; sem outro lado; sem pregas; sem dobras; sem avesso; sem linha de fuga, nos termos utilizados por Jean Baudrillard ao longo de sua ensaística. Nas imagens embaçadas, de luz mortiça, coadas pelo vidro leitoso teríamos, em suma, a negação do mundo sem falhas, de uma continuidade sem fissuras, próprio à ordem dos simulacros, da hiper-realidade das imagens, de alta definição, intensíssimas do ponto de vista sensorial.

É o que ocorreria em obras, tais como a Kunsthaus, de Peter Zumthor (Bregenz, 1991), a Galeria Goetz, de Herzog \& de Meuron (Munique, 1992) ou o Instituto Moreira Salles (São Paulo, 2oII), segundo Wisnik. Lançando o olhar desde fora destes edifícios é possível ver em seu interior, em virtude da luz que atravessa a pele semifosca ou turva de seus envoltórios, somente silhuetas bruxuleantes. Neste conjunto de obras, o autor também inclui a Fundação Cartier para a Arte Contemporânea, de Jean Nouvel (Paris, 1994), apesar da singularidade desta construção; pois nela não há peles túrgidas, como nos casos anteriores, mas "planos paralelos de vidros, alguns apenas cenográficos, sem qualquer função real que não seja a de criar efeitos ambíguos de visão", dos quais resultaria "um rico baralhamento perceptivo entre o edifício, os jardins interiores e o contexto urbano". "Com rara sensibilidade plástica, Jean Nouvel [- conclui Wisnik seu

\footnotetext{
is WISNIK, Guilherme. 20I8, p. 9.

${ }^{16}$ Ibid., p. I5.
} 
comentário a Fundação Cartier -] consegue ali dissolver a leitura de um volume sólido por meio daquilo que ele mesmo denominou poética da bruma e da evanescência" ${ }^{17}$ É possível indagar, no entanto, apesar da leveza minimalista comum a esses edifícios, se não teríamos na Fundação Cartier, de Jean Nouvel, um virtuosismo formal que não encontramos nos demais edifícios. $\mathrm{O}$ efeito de dissolução da estrutura do edifício da Fundação, em estranha atmosfera enevoada, não seria tão cenográfico - apesar da imensa distância formal que os separa - quanto o envoltório exibicionista, em placas de titânio, do Museu Guggenheim de Frank O'Gehry (Bilbao, 1997)?

Neste aspecto, Wisnik afasta-se de Hal Foster, para o qual o poder de resistência da arquitetura (ou sua qualidade formal, ético-estética) residiria na dialética entre a tectônica (o literal, ou estrutura) e a pele (a imagem, ou superfície). Esta dialética entre "literalidade" e "efeito fenomênico", ou materialidade e imaterialidade, só excepcionalmente, no entanto, estaria assegurada, como em certas obras de Herzog \& de Meuron, Kazuyo Sejima (ao qual voltaremos), e Richard Gluckman; porque a dominante no estilo global dos starchitects, ainda segundo Hal Foster, seria o predomínio do "fenomênico" sobre o "literal”. É o que se evidenciaria, por exemplo, na Fundação Cartier, porque aqui, a caixa de vidro não operaria como transparência literal ou clareza estrutural no sentido da arquitetura miesiana, mas como envoltório que sobrepuja, senão "humilha a estrutura" ${ }^{18}$ Neste edifício, a paliçada de vidro faria com que o literal se tornasse rarefeito e o fenomênico se intensificasse como brilho, ou se esvaecesse como bruma, de acordo com a hora do dia. Seria uma arquitetura, segundo Foster, que visaria a produzir atmosferas, "deslumbrando" o observador, como se o seu modelo ideal fosse uma "joia iluminada"; ou as mercadorias de luxo. ${ }^{19}$

A névoa é um tópos, originário da prática da pintura. Basta lembrar as formas brumosas - como a "fumaça que se mistura ao ar empoeirado quando atinge certa altura" como descrevia Leonardo da Vinci no Tratado de pintura $;{ }^{20}$ os nenúfares de Claude Monet; os sfumatos de Odilon Redon; as vaporizaçôes de J.M.W.

\footnotetext{
${ }^{17} \mathrm{Id}$.

I8 FOSTER, Hal. O complexo arte-arquitetura. São Paulo, Cosac \& Naify, 20I5, p. I5I.

19 Ibid., p. 152.

${ }^{20}$ DA VINCI, Leonardo. Tratado de pintura. 7ª edição. Madri, Akal, 2oIo, p. 344-345.
} 
Turner; e, na linha pictorialista da fotografia, as nuvens de Alfred Stieglitz que levam ao apagamento do referente (do objeto como um dado lugar), colocando a imagem além das qualidades inerentes do referente, de tal modo que ele, o objeto, não seria mais observado "pelo seu aspecto exterior, mas segundo as regras do belo pitoresco", nos termos do pintor oitocentista William Gilpin; ${ }^{21}$ as pinturas de luz branco nácar de Armando Reverón; ou, por fim, as aquarelas do Atlas pitoresco dos céus de Hércules Florence, entre tantas referências pictóricas ou de fotografias pictorialistas, de névoas.

São diversos os sentidos atribuídos às névoas ao longo do livro. Elas são "sinais tanto negativos quanto positivos no mundo atual”, "afinal, a nuvem (ou névoa) destaca o autor - não é unívoca”, mas plural. ${ }^{22}$ A névoa é utilizada, em primeiro lugar, para figurar os eventos de destruição ou morte nos séculos XX e XXI. Daí, as menções do autor às nuvens radioativas provocadas pelo lançamento de bombas atômicas, em 6 de agosto de 1945, sobre as cidades de Hiroshima, e, três dias mais tarde, sobre a cidade de Nagasaki, no Japão (que foram vertidas em serigrafias de séries de cogumelos edulcorados por Andy Warhol, nos anos 1960); a nuvem negra de detritos produzida pela implosão do conjunto habitacional Pruitt-Igoe, de Minoru Yamasaki, em St. Louis, Missouri, às ish32, de is de julho de 1972, que foi tomada pelo historiador Charles Jencks, em livro de 1977, como marco do fim da "Ideologia do Plano" da arquitetura moderna ou e do início da arquitetura dita pós-moderna; e, por fim, a nuvem branco-amarelecida composta de pó de mármore, betão, aço e açôes financeiras, que engolfou vários quarteiróes de Manhattan, após o ataque da Al-Qaeda, em II de setembro de 20or ao World Trade Center, projetado por Yamasaki, Leslie E. Robertson e Emey Roth \& Sons. ${ }^{23}$

${ }^{21}$ Cf. GILPIN, William. An Essay on Prints. Londres: Creative Media Partners, 2019.

${ }^{22}$ WISNIK, Guilherme. 2018, p. 307.

${ }^{23}$ Sobre o ataque às Twin Towers, afirma Wisnik: "É o que vemos nas impressionantes fotos de rua daquele dia: um terrível tufão produzido pelo homem, na escala monumental de uma cidade de torres, como uma apocalíptica catástrofe pós-natural, despejando uma chuva de poeira e papéis sobre a cidade (ações, títulos financeiros, capital flutuante?), numa espécie de carnaval sinistro. E, para além disso, a fumaça negra do incêndio nas torres - como se a cidade estivesse subitamente se transformado em um campo de exploração de petróleo -, a fumaça branca do momento das suas quedas, a nuvem amarelada que pairou nos extratos mais baixos da cidade 
A névoa, em Dentro do nevoeiro, é também uma imagem para o estágio atual do capital financeiro ou imaterial, porque sem lastro no mundo dito real. É a imagem do capitalismo da rede digital, do movimento incessante de informaçóes e de capital especulativo pelo mundo global: "Não é [apenas] uma imagem da evolução tecnológica sem que esta seja, mais profundamente, uma mutação do capitalismo", dizia, nesta direção, Gilles Deleuze. ${ }^{24}$ A névoa é nuvem (cloud) "invisível e onipresente", carregada de megadados e algoritmos que pairam acima de nossas cabeças. ${ }^{25} \mathrm{~A}$ nuvem é tão abstrata quanto concreta haja vista que rastreia todas as nossas açốes: "O marketing é agora o instrumento de controle social, e forma a raça impudente de nossos senhores" - “a empresa”. ${ }^{26}$ A nuvem é a sociedade de controle [e não a sociedade disciplinar, no sentido "moderno"], de

depois disso, depositando-se em forma de fuligem sobre as pessoas, e a intensa neblina cinzenta que cobriu Nova York por semanas, e que, em termos simbólicos, permanece ainda no ar, dando a impressão de que não se dissipará tão cedo. Prenúncio, talvez, da nuvem tóxica do capital financeiro em combustão que atingiu a cidade (e o mundo) sete anos depois, com a quebra do banco de investimentos Lehman Brothers, em Is de setembro de 2008, - sendo essa outra nuvem, como está claro, apenas simbólica”. (WISNIK, Guilherme, op. cit., p. 153). Permito-me acrescentar a esse rol de névoas tanatológicas, as nuvens esverdeadas transmitidas pela televisão, ao vivo, para o mundo inteiro, em I7 de janeiro de 1991, provocadas pelos bombardeios do Kuwait e Iraque pelos Estados Unidos, que então liderava uma força de coalizão internacional, deflagrando, via satélite, a "Guerra do Golfo": "Na TV, a Guerra do Golfo era um espetáculo instantâneo que dispensava toda mediação narrativa como interpretação da historicidade do evento, pois evento e relato eram simultâneos. Nunca se via a morte, mas sua ficção natural, amplificada nos modos racionalizados da sua produção como uma natureza fictícia: os bombardeios sobre Bagdá eram ecleticamente lindos, verdes e azuis pós-utópicos de mísseis desconstrutores, nuvens amarelas de explosôes e cortinas negras de ideologia, roxo escurecidas de fumaça neoliberal contra um céu azul-cobalto fundamentalista, ritmados dialeticamente pela harmonia curda dos desabamentos performáticos - como um cenário de Spielberg, um filme de Greenaway, uma tela neobarroca, um vídeo neokitsch, a ópera total, wagneriana e portátil, consumida em casa na total equalização dos tempos, contemporânea como a novela de cavalaria, o império romano, o marketing político da ética e da moral, os discos voadores, a falta de assunto e as pipocas”. (Cf. HANSEN, João Adolfo; "Pós-moderno \& cultura". In: Samira Chalub (Org.). Pós-moderno: semiótica, cultura, psicanálise, literatura, artes plásticas. Rio de Janeiro, Imago, 1994, p. 80).

${ }^{24}$ DELEUZE, Gilles. "Post-scriptum sobre as sociedades de controle”. In: Conversaçôes: 1972199o. São Paulo, Editora 34, 1992, p. 223.

${ }^{25}$ WISNIK, Guilherme. 20I8, p. IоI.

${ }^{26}$ DELEUZE, Gilles, p. 224. 
um controle que é "de curto prazo e de rotação rápida", "contínuo e ilimitado", que "detecta a posição de cada um, lícita ou ilícita", operando uma "modulação universal", ainda segundo Deleuze. ${ }^{27}$

A névoa, enfim, - na condensação de Wisnik - figura o "sublime digital" ${ }^{28}$ Pode-se, de fato, evocar o sentimento do sublime em face da nuvem digital, porque esta implica aquilo que por ser demasiadamente grande, escapa a toda medida, a qualquer tentativa de sua subsunção às categorias do pensamento. $\mathrm{O}$ "sublime digital" ou "sublime capitalista", nos termos utilizados pelo autor, corresponde à noção, aparentemente paradoxal, de "sublime imanente" de Jean-François Lyotard. ${ }^{29}$ O sublime imanente é, segundo Lyotard, o "fato essencial da pós-modernidade", a saber: o de que a lógica do capitalismo e da tecnociência é a desmedida, uma vez que são as "possibilidades infinitas de transformações e operações dos aparelhos que póem em movimento esta mesma lógica"; que foi caracterizada por Lyotard, em $A$ condição pós-moderna como "performances do sistema", incluindo-se nestas, "sua própria otimização": o "crescimento do poder e sua autolegitimação pela produção, memorização, acessibilidade e operacionalidade das informações" ${ }^{30}$

O sentimento de sublime em face da nuvem digital não "faria, em suma, acreditar na realidade deste mundo", mas "permitiria descobrir a sublimidade que o sustenta": o investimento libidinal, sempre crescente, na "arma-instrumento" no termo estratégico utilizado por Lyotard em sua caracterização da racionalidade técnico-científica "pós-moderna". ${ }^{3 \mathrm{I}} \mathrm{Na}$ noção de sublime digital temos um aggiornamento da estética do sublime com a substituição do sublime transcendente (que autores como Jameson e Lyotard associam à "estética da modernidade") pelo sublime imanente, o que significa dizer que a Ideia de uma razão emancipadora que visa à totalidade foi substituída pela ideia de um puro artifício, que segue a lógica da performance, em contínua expansão da tecnociência. Sendo assim a

${ }^{27}$ Ibid., p. 225 .

${ }^{28}$ WISNIK, Guilherme, op. cit., p. IoI; 297.

${ }^{29}$ Ibid., p. 297. Cf. também LYOTARD, Jean-François. L'assassinat de l'experiénce par la peinture: Jacques Monory. Pandin, Le Castor Astral, 1984, p. 74.

${ }^{30}$ LYOTARD, 1984, p. 108. Cf. também, LYOTARD, Jean-François. O pós-moderno. Rio de Janeiro: José Olympio, 1984, p. XVII.

${ }^{3 \mathrm{I}}$ LYOTARD, J-F. L'assassinat de l'experience par la peinture: Jacques Monory, p. I49. 
névoa figura a desmesura do mundo digital, com sua intensidade espectral, vazia de sentido, própria ao fetiche, que é fonte de fascínio.

A névoa opera também, neste livro, como imagem da indeterminação. Estamos vivendo, segundo o autor, dentro do nevoeiro, afastando a ideia de fatalidade ou de caminho de mão única na história. Guilherme Wisnik constrói, em outros termos, uma dialética das nuvens: uma oposição entre o mundo virtual, baseado na instantaneidade das informações (o sublime digital) e a poética do nublamento, entendida como formas internas de resistência a esse mesmo mundo global. Se, por um lado, a névoa é metáfora do sublime capitalista, baseado na nuvem da informática, dos algoritmos de controle e da volatilidade das açốes financeiras, como vimos; por outro lado, a névoa é também um índice de indefinição em relação ao futuro, como se evidencia em certa arte e arquitetura recentes: "Afinal, dentro da nuvem, isto é, no mundo atual, a luz é difusa, não permitindo a definição nem de centros nem de margens em sua emissão e recepção. Habitamos assim, - nos termos de Jeffrey L. Kosky - um global blur, um desfocamento global". ${ }^{32}$

Estar em meio à névoa é viver, assim, a experiência da imponderabilidade do devir, ou seja, de que algo diverso do que está dado está na iminência de advir. Essa associação do nevoeiro ao advento do novo (de um "outro novo", porque não se trata mais do velho novo moderno), daquilo que se entrevê em meio ao velamento do presente, remonta, segundo Wisnik, aos "mitos-poéticos ameríndios" analisados por Lévi-Strauss, segundo o qual, o denso nevoeiro que subitamente baixa interpondo-se aos homens e seu ambiente teria "um papel cosmogônico, de interrupção e de reinstauração do mundo, alterando abruptamente a ordem das coisas": "é o véu que cobre por um instante a realidade, desencadeando uma situação a partir da qual as coisas se transmutariam e trocariam de posição". ${ }^{33}$ No mundo atual, as névoas, como no mito descrito, também operariam como sinais de transformação, não porque refundariam em novas bases o mundo existente como na cosmogonia ameríndia, mas porque permitiriam entrever índices de liberdade (de invenção de possíveis) em meio à naturalização do capitalismo digital-neoliberal.

É na "poética do nublamento" (já introduzida a propósito dos vidros leitosos) que o autor localiza formas residuais e emergentes de resistência à arte e

${ }^{32}$ KOSKY, Jeffrey L. Apud WISNIK, Guilherme. 20I8, p. 289.

33 WISNIK, Guilherme. op. cit., p. II9; 255 . 
arquitetura hegemônicas no capitalismo neoliberal, tais como as fotografias de Michael Wesely; as instalações de Olafur Eliasson; e as "construções" do escritório SANAA de Kazuyo Sejima e Ryue Nishizawa; e do escritório Diller + Scofidio, de Elizabeth Diller e Ricardo Scofidio. São alguns exemplos, retirados do autor, que permitem especificar o sentido que ele atribui à poética do nublamento como forma de resistência.

Com "câmeras especiais" que "filtram enormemente a luz que atinge o filme", Michael Wesely "registra cenas" que se "estendem por um tempo muito longo". ${ }^{34}$ Dilatando "enormemente o instante do clique fotográfico em minutos, horas, dias, meses ou anos, o fotógrafo dá assim uma feição surpreendentemente tangível à duração temporal, normalmente alheia ao universo instantâneo da fotografia". ${ }^{35}$ É o caso das fotografias da reconstrução do conjunto Potsdamer-Leipziger Platz, em Berlim, de 1997 a 2000, desenhada por Renzo Piano, Richard Rogers e Helmuth Jahn: "uma minicidade evento" - na expressão de Otília Arantes - 36 "que se define como um parque temático [um centro internacional de comunicação, mídia e serviços] encravado no coração da cidade, emulando uma falsa condição de espaço público misturado". ${ }^{37}$ Nessas imagens o que vemos é "um emaranhado de formas sobrepostas: edifícios em construção fundindo-se em formas espectrais, o skyline da cidade por trás, gruas e andaimes por toda parte, brilhos e luzes refratados e o desenho cambiante do percurso do sol no céu ao longo das estaçóes do ano", na écfrase do autor. ${ }^{38}$

Numa reação à redução da Potsdamer Platz a um cenário de puro artifício high-tech que produz estranho fascínio pela desaparição da história (após a queda do Muro de Berlim), as fotografias de Wesely visam a restituir-lhe sua concretude física e densidade temporal. Essas fotografias entremostrariam, assim, nas camadas sobrepostas de tempo, o canteiro de obras com os andaimes que estruturam o edifício - "o processo material que está por trás da cena enquanto resultado de uma cadeia produtiva” - numa recusa à redução da arquitetura à

34 Ibid., p. 133 .

35 Id.

${ }^{36}$ ARANTES, Otília. "Berlim reconquistada”. In: Berlim e Barcelona: duas imagens estratégicas. São Paulo, Annablume, 2012, p. I25.

${ }^{37}$ Ibid., p. II2.

${ }^{38}$ WISNIK, Guilherme, op. cit., p. 137. 
forma significante ou à forma-simulacro (às imagens espetaculares no capitalismo tardio)..$^{39}$

Destaquem-se dois aspectos que já estão indiciados no livro, nos quais reside, ao meu juízo, o potencial crítico das fotografias de Wesely, a saber: o palimpsesto e a duração. Nos véus sobrepostos nas fotografias da Potsdamer Platz, temos algo análogo ao "palimpsesto", a escrita sobre a escrita, ou ao pentimento, na pintura. Neste último caso, as camadas superpostas da praça em construção (que também evocam ruínas de um sítio arqueológico) são como as veladuras de uma pintura; como os véus sucessivos de cor que a tornam luminescente, uma vez que a veladura não é opaca, mas translúcida. Assim como na veladura ou na encáustica que valorizando o valor da cor (sua luminosidade) deixa entrever as tonalidades das camadas inferiores de tinta, na fotografia da Potsdamer Platz de Wesely é possível apreender "tudo o que esteve presente diante da câmera durante todo o tempo" em que sua objetiva manteve-se aberta. ${ }^{40}$ Em suma: o que se vê, neste caso, são as finíssimas camadas translúcidas de cor-luz, situadas entre a transparência e a opacidade.

Motivado pelo texto do autor, acreditando manter-me fiel ao seu teor, pode-se acrescentar que tanto nas "camadas de tempo que se espacializam" ${ }^{41}$ nas fotografias de Wesely quanto no pentimento, entendido como folheado de camadas de tinta, há um mesmo "efeito-afeto de indeterminação", que não pode ser subsumido ao dispositivo representacional, haja vista que ele introduz "o irrepresentável" na constituição mesma da "representação mimética" (das gruas e andaimes da Potsdamer Platz), levando-a ao limiar da desaparição. ${ }^{42}$ Desestabilizar-se-ia, assim, nos dois casos, a estrutura habitual da percepção ao se substituir a oposição, ou mesmo a reversibilidade, entre figura e fundo (o espaço óptico) pela porosidade, senão indistinção, entre as superfícies de cima e a de baixo (o espaço tátil). É o que se verifica, vale notar, em artistas como Cézanne, Jean Fautrier, Jean Dubuffet, François Rouan, Jackson Pollock, Julian Schnabel, Anselm Kiefer, ou ainda Gerhrad Richter (citado pelo autor). É verdade que o efeito de suspensão da

39 Ibid., p. 139.

${ }^{40}$ Ibid., p. I33.

${ }^{41} \mathrm{Id}$.

${ }^{42}$ LACAN, Jacques. Seminário, livro II: os quatro conceitos fundamentais da psicanálise. Rio de Janeiro, Zahar, 2008, p. 76 . 
nitidez das formas nas obras desses artistas é resultado do manuseio dos pigmentos, ou da rugosidade dos empastes, enquanto nas fotografias diáfanas de Wesely o efeito de nublamento, ou de películas de luz, são obtidos em filmes fotossensíveis.

O segundo aspecto que atribui às fotografias da Potsdamer Platz um enigma é a incorporação, nelas, da duração. A utilização de câmeras com abertura por longa duração do diafragma estende o "instante decisivo" na fotografia, na expressão de Henri Cartier-Bresson, à duração do plano-sequência cinematográfico (ou do vídeo). Situando-se entre a imagem estática e a imagem dinâmica, a fotografia de Wesely possibilita, assim, pela dilatação do instante, a cristalização do tempo, enquanto duração, em uma dada imagem. Seu intento é estender o instante decisivo tornando-o imagem-tempo (ou duração) e na mesma operação aproximar a imagem-movimento (própria ao cinema) da imobilidade do fotograma, tensionando assim os regimes temporais da "forma fotografia" e da "forma cinema (ou vídeo)" ${ }^{43}$ A imagem fixa da Potsdamer Platz aspira, em suma, à mobilidade da imagem fílmica no intento de apreender a dimensão processual das coisas e dos fatos, ou seja, a sucessão causal dos eventos no tempo: ou ainda, o processo de gentrificação promovido pelo "Planejamento estratégico" da cidade de Berlim, no período da reunificação, que se seguiu à Queda do Muro, em conformidade com os imperativos do capitalismo pós-industrial ou financeiro. $\mathrm{Na}$ fotografia de Wesely evidencia-se o que a Potsdamer Platz high-tech e glamourizada visa a ocultar: a ação predatória do capital corporativo global que apaga o continuum da história. Essa fotografia reage, retomando os termos de Dentro do nevoeiro, à "falta de espessura histórica" da arquitetura-icônica, ou da imagem publicitária como forma-mercadoria, nas Global Cities, em prol da "qualidade de uso do lugar na vida real". ${ }^{44}$

É possível acrescentar, ainda a propósito da duração, que a fotografia de Wesely impóe dada temporalidade à fruição do observador. Diante da pergunta: "o que suas imagens esbatidas, nas quais toda a nitidez é suspensa, esperam de nós?”; pode-se responder que é a tékhne da demora: a percepção ciosa e morosa, ou seja, o tempo necessário para que "na observação dessas imagens comece a

${ }^{43}$ FATORELLI, Antonio. Fotografia contemporânea: entre o cinema, o video e as novas midias. Rio de Janeiro, Senac Nacional, 2013, p. I77.

44 WISNIK, Guilherme. 20I8, p. I35. 
nascer tudo o que nela, ou em face dela, efetivamente aconteceu": a construção da praça. ${ }^{45}$ Essa abertura da imagem à "intratável realidade” (Jean Baudrillard), que remete à noção de punctum em Roland Barthes, pode ser sintetizada na interjeição: "Isso foi!". ${ }^{4}$ Essa expressão, no entanto, não deve ser entendida como a fixação de um instante, como quer Barthes, mas como a apreensão do processo de transformação da cidade (ou de apagamento de sua história), de algo que lá ocorreu absolutamente, irrecusavelmente, no presente (contínuo), em face da câmera. São fotografias que atestam, assim, a teimosia do "Referente", de afirmar-se como "realidade ontológica": a construção real da Potsdamer Platz (de seus edifícios e entorno). ${ }^{47}$

Por isso, as fotografias de Wesely são belas imagens pensativas, imagens que forçam sensivelmente o pensamento (porque nelas não há ponto que não nos mire) inquirindo-nos, em oposição às imagens intensíssimas do ponto de vista sensorial, que são, porém, vazias, porque desvinculadas da experiência vivida ou da memória coletiva. Nelas, encerra-se pensamento não pensado, pensamento não atribuível diretamente seja à intenção do fotógrafo, seja a um objeto determinado (o studium, segundo Barthes. Ou seja, a Potsdamer Platz como referente). A imagem pensativa abre, assim, uma "zona de indeterminação" entre "presença e ausência", nos termos de Baudrillard, ou "entre pensamento e não pensamento, entre atividade e passividade, e mesmo entre arte e não arte, na medida em que redefine a fronteira entre esses termos" ${ }^{48}$ A imagem pensativa contrapóe, dito de outro modo, "a força de pensatividade do punctum ao aspecto informativo representado pelo studium"; ${ }^{49}$ ou seja, a imagem pensativa desencadeia uma paixão escópica, ou uma "loucura do olhar", na expressão de Barthes: uma circularidade feita de um vai e vem que não cessa entre distintos modos de enunciação, entre "o saber de um objeto representado" e o "não-saber que força o pensamento". .० $^{\circ}$

${ }^{45}$ KIAROSTAMI, Abas. Apud FATORELLI, Antonio, op. cit., p. I27.

${ }^{46}$ BARTHES, Roland. A câmara clara: notas sobre a fotografia. Rio de Janeiro, Nova Fronteira, I984, p. I5.

$47 \mathrm{Id}$.

${ }^{48}$ RANCIÈRE, Jacques. O espectador emancipado. São Paulo, WMF; Martins Fontes, 2oI2, p. I05.

59 Ibid., p. 4I. 
É dessa zona de indiscernibilidade (a "figurabilidade", diria Lyotard), que é o próprio imponderável, que resulta o efeito de "distância", ou de "certo mistério", dessas imagens..$^{\mathrm{sI}}$ As fotografias de Wesely interrompem assim toda organização performativa, toda convenção ou contexto dominável pelo convencionalismo da máquina geradora de imagens da mídia digital e de massa que é sempre tautológica, porque resultado da permutabilidade generalizada das imagens-fetiches.

Como segundo exemplo da poética do nublamento, destaque-se, entre os mencionados pelo autor, a instalação em site especific, The weather project, de Olafur Eliasson, apresentada na Turbine Hall da Tate Modern, em 2003. Essa instalação era "constituída de um semidisco metálico estruturado por andaimes e iluminado com lâmpadas de monofrequência. Além disso, o artista instalou um espelho rente ao teto do salão, duplicando o espaço e refletindo suas imagens - a arquitetura, as pessoas e o próprio meio sol, que, ao se duplicar, completava-se -, além de envolvê-lo em uma bruma artificial, cujo ar de mistério potencializava o

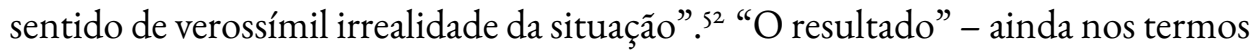
de Wisnik - "é que as pessoas acorriam em grande número para o museu, durante o inverno londrino, com a intenção de se deitar no chão daquela praia artificial e receber na pele - ainda que apenas de forma mediada pelos olhos e pelo cérebro, porém de modo muito verossímil - a energia daqueles benéficos raios solares". ${ }^{33}$

É possível também, a nosso ver, associar "esse ar de mistério" evocado pelas brumas - na fruição desta instalação de Eliasson - ao "sentimento do sublime" kantiano. Na Turbine Hall, uma antiga usina elétrica, hoje desativada, o visitante se defronta com o "absolutamente grande"; com algo "que em comparação com o qual tudo o mais é pequeno", vivendo um "sentimento simultâneo de fascínio e terror", no qual "o prazer só é possível mediante um desprazer", tal como aquele que entra pela "primeira vez" na Igreja de São Pedro em Roma, no exemplo de Kant. ${ }^{54}$ Essa fruição seria assim, análoga ao sentimento do "sublime matemático"

${ }^{51}$ Ibid., p. 89.

${ }^{2}$ WISNIK, Guilherme, 20I8, p. 28I

53 Ibid., p. 283.

54 KANT, Immanuel. Crítica da Faculdade do Juizo. Tradução de Valério Rohden e António Marques. Rio de Janeiro, Forense Universitária, 1993, p. 26; 98. Fazemos esse paralelo ressalvando que o sublime, para Kant, não é o objeto, mas sim a disposição de espírito através de uma representação que ocupa a faculdade de juízo reflexiva. 
caracterizado por Kant pela inadequação entre a imaginação em sua aspiração ao progresso infinito, à totalidade, enquanto ideia da razão, e a faculdade capaz de avaliar tal grandeza. Desta fruição decorreria, nos termos agora de Lyotard, que retoma ao seu modo a "analítica do sublime" de Kant, um sentimento de suspensão entre o tempo presente e aquele que se anuncia sem jamais se realizar. No bruxuleio de cor-luz da Turbine Hall, o que ocorre é assim o que nele próprio se anuncia, a indagação: "Algo ocorrerá?". 55 É na sustentação dessa interrogação, na expectativa de que alguma coisa surja ou ainda, na espera por algo que "aconteça no acontecimento", que se evidenciaria a possibilidade de que lugares que ainda não tiveram lugar venham a ter lugar. ${ }^{56}$ É na fruição, suspendendo toda a relação de dominação - assim como no juízo reflexivo kantiano, no qual não há subjugação da sensibilidade pelo entendimento, ou do entendimento pela sensibilidade, mas o livre jogo dessas faculdades - que advém a expectação de que alguma coisa haverá de surgir em razão de um impulso que parece forçar a forma (ou seja, que precipita a ambiência de luz em The weather project) para fora de si mesma, para o informe, entendido como índice de alternativas ao real. Isso não significa tomar essa fruição como uma experiência de transcendência pela "apresentação do inexprimível” (no sentido da tradição romântica e da arte de vanguarda como a de Mondrian, Kandinsky ou Malevitch, nos exemplos do próprio Lyotard), mas como "apresentação negativa”, na medida em que há nela uma alusão a algo que não pode ser mostrado, ou "apresentado" - Darstellung no termo de Kant. ${ }^{57}$

Esse espargimento de cores luzes pelo Sol artificial, do amarelo, laranja, vermelho, ou ocre, sempre iridescentes, possibilita ao fruidor o aguçamento de sua sensibilidade à medida que ele caminha pela Turbine Hall. Deslocando-se pelo amplo espaço vazio ele o apreende como totalmente matizado; ou seja, dá-se conta que seu entorno é sempre "furta-cor", uma vez que ele muda sutilmente de aspecto, em função da inclinação de seu olhar. Estamos próximos, aqui, do intento de Hélio Oiticica de ampliar a experiência sensorial pela "corporificação"

"s LYOTARD, Jean-François. O inumano: consideraçôes sobre o tempo. Lisboa, Estampa, 1989, p. 96.

${ }^{56}$ LYOTARD, Jean-François. Que Peindre?: Adami, Arakawa e Buren. Paris, Éditions de la Différence, 1987 , p. 89.

57 LYOTARD, Jean-François, 1989 , p. 95. 
da "cor-duração" - dos Bilaterais de 1959 aos Penetráveis dos anos 1960 - ao permitir que o participante, "visse, sentisse, pisasse, roçasse a cor" emanada de um suporte material, como placas de madeira ou caixas com pigmentos de cor pura; ; $^{8}$ embora em The weather project de Eliasson não haja a liberação da luminosidade da cor-pigmento, aplicada sobre madeira ou concentrada em recipiente, como em Oiticica, mas sim, a construção de um espaço de cor-luz a partir de lâmpadas de monofrequência, como nos artistas Robert Irwin, James Turrell, ou Anthony McCall do grupo Light and Space.

A percepção pelo fruidor de mudanças cromáticas sutis, à medida que ele se desloca, em meio às brumas, pela Turbine Hall, opera como forma de resistência à sociedade da simulação, uma vez que impede que o olhar fique refém da fascinação fatal das imagens de alta-definiçãoo do mundo digital. Na percepção das nuances da névoa produz-se uma espécie de epokhé, de suspensão provisória da linguagem visual dominante que é tomada, simplesmente, como natural, porque certificada pelas reiteraçôes sem fim da "tela total". ${ }^{99}$ Essa percepção cuidadosa e distendida no tempo - já requerida como vimos pelas fotografias de Wesely - é "uma mercadoria cada vez mais rara, senão um verdadeiro luxo" no mundo colonizado pela decifração imediata, puramente operacional das imagens, tal como ocorre na navegação pela internet; afinal, rapidez, desempenho, performance, são as palavras de ordem do capitalismo digital. ${ }^{60}$ É justamente, no entanto, na percepção marcada pelas hesitações, pela perda de tempo e pelo tempo perdido, pela paciência em desvelar o segredo daquilo que não se deixa apreender de imediato, porque apenas se deixa entrever, que teríamos a negação da temporalidade da produção de imagens clichês (ou seja, da voracidade e da pressa); e por consequência do "hedonismo ansioso", que rege a vida na "hipermodernidade". ${ }^{61}$

O terceiro exemplo de poética do nublamento é o Museu de Arte Contemporânea do Século XXI (1999-2004), em Kanazawa, no Japão, do escritório SANAA

${ }^{58}$ FAVARETTO, Celso. A invenção de Hélio Oiticica. São Paulo, Edusp, 1992, p. 66; 92.

59 BAUDRILLARD, Jean. Tela total, mito-ironias da era do virtual e da imagem. 3 a edição. Porto Alegre, Sulina, 2005.

${ }^{60}$ BARTHES, Roland. O neutro: anotaçôes de aulas e seminários ministrados no Collège de France 1977-1978. São Paulo, Martins Fontes, 2003, p. 27.

${ }^{6 r}$ LIPOVETSKY, Gilles \& SEBASTIEN, Charles. Os tempos hipermodernos. São Paulo: Barcarolla, 2004, p. 55 . 
(Kazuyo Sejima e Ryue Nishizawa), assim descrito por Wisnik:

Por fora, vemos uma superfície centrífuga e contínua, uma fachada curva [um cilindro em vidro]; e, por dentro, um labirinto de percursos entre salas e pátios, no qual os espaços de circulação (os interstícios entre os blocos) se tornam também lugares de estar, ganhando um protagonismo inédito. ${ }^{62}$

Nessa construção, o fundamento é "o grau zero da materialidade e da tectônica", de tal modo que suas paredes são "quase sem espessura" e seus pilares são de uma "esbelteza quase inverossímil". ${ }^{3}$ Subtraindo do edifício seu peso e densidade, o SANAA investe na "qualidade reflexiva e atmosférica" dos vidros "muitas vezes curvos", em "seus diferentes graus de translucidez e opacidade" ${ }^{64}$; de tal modo que "na esteira da tradição cultural milenar do seu país", o Japão, Sejima e Nishizawa saberiam como "construir o vazio". 65

A arquitetura do Museu de Arte Contemporânea do Século XXI extrairia, ainda segundo Wisnik, "um imprevisto sensualismo da inexpressividade" ${ }^{66}$ Sua autoria consistiria, paradoxalmente, "em transmitir um sentimento de anonimato voluntário em um mundo narcisista e exibicionista”, como comprovam as formas exuberantes, ou virtuosísticas, dos starchitects. ${ }^{67}$ Se nestas últimas temos o valor da exibição na produção da forma, naquela haveria sua denegação: uma estética da parcimônia que apagaria, com perícia técnica, a estrutura do edifício. ${ }^{68}$ Nesta

${ }^{62}$ WISNIK, Guilherme. 20I8, p. 25.

${ }^{63}$ Ibid., p. 27.

${ }^{64}$ Ibid., p. 25. É interessante assinalar que Kazuyo Sejima, em chave crítica, associou os níveis de "translucidez e opacidade" de suas formas sinuosas e espectrais, à falta de "profundidade e transparência" do "mundo digital contemporâneo" (opondo-se assim à ideologia, segundo a qual o que vigoraria no mundo virtual é a "plena visibilidade”). Id.

6s Id.

${ }^{66}$ Ibid., p. 23.

67 Ibid., p. 27.

${ }^{68}$ É verdade que o Museu de Arte Contemporânea do Século XXI do SANAA pode ser visto também, vale acrescentar, como um exibicionismo às avessas: como ostentação do comedimento da forma. 
direção, diria que o Museu do Século XXI de Sejima e Nishizawa é uma "arquitetura do desobramento" (désoeuvrement, no termo de Maurice Blanchot); ${ }^{69} \mathrm{e}$ não uma "arquitetura da desconstrução", como a de Peter Eisenman ou Michael Graves que nos anos 1970 desconstruíam, por meio de secçóes longitudinais e transversais, o "signo-sistema" da arquitetura construtiva ou racionalista, a saber: o cubo (numa operação semelhante à desconstrução por Jacques Derrida das noçôes de verdade, sujeito ou consciência, que fundamentam a filosofia da representação).

A arquitetura "à beira do desvanecimento" de Sejima, "que desrealiza os seus perfis em sombras e reflexos", abre, em outros termos, um vazio central, um tempo de silêncio, uma questão sem resposta. ${ }^{70} \mathrm{~A}$ "imaterialidade abstrata dos edifícios do Sanaa”, na formulação de Wisnik, pode ser caracterizada, a meu ver, pela noção de "não-expressão" (no termo utilizado por Theodor Adorno, a propósito de certa literatura moderna); ou ainda: seus edifícios podem ser tidos como uma arquitetura do "sem-expressão"; ou, por fim, da "expressão da não-expressão". ${ }^{71}$ Essa noção de "expressão do sem-expressão" tomada aqui como correlata à noção de suspensão, já mencionada anteriormente, implica a ideia de indeterminação de abertura da forma, no sentido estético e político. ${ }^{72}$

Na fruição da arquitetura do "Museu do Século XXI" de Sejima, enquanto forma do "não subjetivo do sujeito", teríamos, enfim, o páthos da suspensão uma espécie de desnorteio do anseio, que não corresponde à ideia de esperança, no sentido do projeto utópico da arquitetura moderna, mas como dizíamos a propósito da fruição em The weather project de Eliasson - de um sentimento de expectação: "Algo ocorrerá?". O edifício de Sejima é, portanto, uma forma quase imaterial em face da qual "há ainda a experiência da inacessibilidade", sendo que "este $h a ́$ ", "este ai", tendo lugar na forma, como uma presença muda diante do

${ }^{69}$ BLANCHOT, Maurice. O espaço literário. Rio de Janeiro, Rocco, 1987.

70 WISNIK, Guilherme. 20I8, p. 27.

${ }^{71}$ Cf. ADORNO, Theodor W. Teoria estética. Lisboa, Edições 70, 1982.

${ }^{72}$ Esse intento de despersonalização - que atribuímos a Kazuyo Sejima - de desertar da forma arquitetônica a forma do sujeito, tornando impessoal a linguagem (na arquitetura) remete, ainda, às noções de "mutismo"; de "informe", de "neutro" ou de "força de despossessão", presentes em Maurice Blanchot, Georges Bataille, Roland Barthes e Michel Foucault. 
fruidor, "perto dele" e mesmo, "nele": "uma imagem flutuante, adiada", um "tumulto silencioso", agora nos termos de Georges Didi-Huberman. ${ }^{73}$

O quarto exemplo de poética do nublamento que destacamos de Dentro do nevoeiro é o "pavilhão temporário" Blur Building, projetado por Elizabeth Diller e Ricardo Scofidio, para a "Expo 2002, na Suíça, com a consultoria da artista japonesa Fujiko Nakaya" ${ }^{74}$ É uma forma artística ou arquitetônica de exceção, portanto, resistente à arquitetura corporativa hegemônica no mundo global, resultante de efetuações tecnológicas. Sua forma é de baixa definição, porque possui alto nível de opacidade ou indeterminação, produzido a partir de alta tecnologia:

Construído sobre o lago Neuchâtel, em Yverdon-les-Bains (Suíça), Blur Building é [na caracterização do autor que aqui sintetizamos] uma plataforma constituída por uma trama de estrutura metálica vazada, acessível por uma extensa passarela, e envolvida por uma nuvem permanente de água captada no lago que era aspergida por micropulverizadores controlados por computador. ${ }^{75}$

Borrando as fronteiras entre arte e arquitetura, este pavilhão - um "edifício de fumaça com mídia integrada” - parece ser o resultado da transposição do sfumato das pinturas de Leonardo da Vinci para a arquitetura. ${ }^{76}$ Segundo Elizabeth Diller é um "ambiente imersivo no qual o mundo é posto fora de foco, enquanto nossa dependência visual é posta no foco [no centro]"; ou seja, em face dele não haveria "nada para se ver além da nossa própria dependência da visão". ${ }^{77}$

Pode-se a partir dessa descrição de Diller caracterizar a fruição dessa plataforma como a percepção de uma forma arquitetônica in status nascendi. Numa arqueologia do olhar, o fruidor, em estado de expectação apreenderia uma formaimagem ainda indefinida, mas que estaria na iminência de vir a lume. É preciso

${ }^{73}$ DIDI-HUBERMAN, Georges. O que vemos, o que nos olha. São Paulo, Editora 34, 1998, p. $129 ; 169$.

74 WISNIK, Guilherme, op. cit., p. 29I.

$75 \mathrm{Id}$.

${ }^{76} \mathrm{Id}$.

77 DILLER, Elizabeth. Apud WISNIK, Guilherme. 20I8, p. 29I. 
descer às névoas (ao ofuscamento) para então aceder, outra vez, à visão; ou seja, para ver as coisas, novamente, como se elas fossem vistas pela primeira vez. As névoas são assim a negatividade (o informe) que antecipa a imagem (a forma), ou ainda, a pré-imagem que está na origem da ordem das coisas visíveis. Nesse sentido é que essa "arquitetura como atmosfera" ao produzir a "obstrução forçada da visão" adquire uma dimensão crítica, na medida em que ela se opõe ao "rápido consumo visual", ou seja, ao pronto reconhecimento dos signos, na sociedade do espetáculo (na qual "a imagem [clichê] é a forma final da reificação da mercadoria”, como dizia Guy Debord).$^{78}$

O Blur Building, uma "arquitetura in absentia", visava a produzir, segundo o próprio arquiteto Ricardo Scofídio, um "sublime tecnológico" (que é preciso diferenciar das noçốes de "sublime digital", "sublime capitalista" ou "sublime imanente", que foram apresentadas acima)..$^{79}$ Para o crítico Mario Costa, em sintonia com os estudos de Lyotard sobre a "Crítica do Juízo" de Kant, seria as novas tecnologias o lugar privilegiado para a produção de "sentimentos contrastantes": "o sentimento negativo de terror ou de impotência" e o "sentimento contrário de maravilha, admiração e estima". ${ }^{80}$ Seriam as novas tecnologias que poderiam revelar “à nossa natureza física seus próprios limites”, ao mesmo tempo em que a "nossa natureza racional perceberia a própria superioridade". ${ }^{8 \mathrm{I}}$ Produziriam "uma experiência negativa e apavorante" - continua Costa em ambiência kantiana "o esforço ingente de superação de nossos limites" - revelando, paradoxalmente, "o caráter ilimitado e infinito de nossa finitude". ${ }^{82}$ As brumas microprocessadas realçariam, em outros termos, a experiência comum de se ser finito e ao mesmo tempo possuidor, na expressão de Kant, de um "pensamento infinito". ${ }^{83}$ Elas aludiriam ao que existe de irrepresentável, àquilo que ultrapassa a representação possível. A "faculdade de julgar reflexionante" ativaria, enfim, a imaginação "em direção a um progresso infinito", "à pretensão à totalidade que não pode ser

\footnotetext{
${ }^{78}$ RENDELL, Jane. Apud WISNIK, Guilherme, op. cit., p. 293.

79 WISNIK, op. cit., p. 30 .

${ }^{80}$ COSTA, Mario. O sublime tecnológico. Experimento, 1995, p. 22.

${ }^{8 \mathrm{I}} \mathrm{Id}$.

${ }^{82} \mathrm{Id}$.

${ }^{83}$ KANT, Immanuel. Critica da faculdade do juizo, p. 139; 142.
} 
objeto dos sentidos" (em efetuação análoga a dos polens de luz dourada na Turbine Hall em The weather project de Eliasson) ${ }^{84}$ Esse novo universo técnico do sublime tecnológico que é deslocado por "Diller + Scofidio" em Blur Building, das instalaçóes no interior de galerias de arte ou de museus para a arquitetura em seu entorno, no seio da cidade, opóe-se, assim, ao grande número de imagens ocas, imagens sem presença, que nada representam além do vazio, como a dos filmes blockbusters que tomam a virtuosidade técnica como efeitismo obrigatório; assim como às imagens dos videogames, que estimulam a interatividade, aqui entendida como interação com o vazio, ou como convivialidade fantasma: a modalidade hoje hegemônica de passividade.

Estes são alguns exemplos da poética do nublamento, na arte e na arquitetura amealhadas de Dentro do nevoeiro de Wisnik, que aqui comentamos livremente, assumindo o risco de infidelidade ao autor. Nesta poética, a névoa opera como forma de resistência à "hipervisibilidade que embasa o sistema de falsas transparências" da sociedade atual. ${ }^{85}$ Nas obras que analisa, o autor aproximando-se de Hal Foster relaciona a arquitetura contemporânea ao minimalismo nas artes, embora haja uma distância no modo como os dois autores concebem a arte minimal. Na recuperação do debate que remonta aos anos 1960, sobre a fruição de uma obra minimalista, Foster afirma que diante dos objetos de artistas como Donald Judd ou Dan Flavin, o fruidor desloca-se incessantemente da "forma objetivada" às suas "configurações sensíveis" e vice-versa; o que não ocorreria na percepção das instalaçôes "imersivas", "tecnossublimes" dos minimalistas James Turrell e Robert Irwin, porque nestas vigoraria um "abuso sensorial". 86 "Contra as tendências contemporâneas de apagamento e sublimação da tectônica e da materialidade na arte e na arquitetura”, Hal Foster acentuava, assim, a necessidade de se preservar "a tensão entre o literal e o fenomênico", ou, como dizíamos, "entre forma objetiva e forma percebida" ${ }^{87}$

Cabe lembrar que a insistência de Hal Foster na evidência do material e da estrutura - índices da velha ordem industrial capitalista - operava como resistência

\footnotetext{
${ }^{84}$ Ibid., p. 17; 19; 40.

${ }^{85}$ WISNIK, Guilherme. 20I8, p. 273.

${ }^{86}$ FOSTER, Hal. 20I5, p. 230-243.

87 WISNIK, Guilherme, op. cit., p. 33; 85.
} 
à atrofia generalizada do tectônico, bem como ao triunfo da pele ou da imagem edulcorada, na arquitetura do projeto digital, autogerado por softwares de alta tecnologia cegos à presença do fruidor. Foster especificava sua concepção de fruição mostrando, por exemplo, como a megaescultura de Serra, The matter of time, no Museu Guggenheim de Bilbao, de Frank O'Gehry, possibilita ao fruidor uma experiência de tempo e lugar, perceptiva e cognitiva, alterando sua percepção de peso, escala, ou duração à medida que ele escolhe, dentre as alternativas abertas pelas placas autoportantes, que direção tomar, para então a cada novo passo no interior dessas espirais de aço criar um novo "lugar"; enquanto a fachada cenográfica deste $M u s e u$, que abriga esta megaescultura, seria um efeito-fátuo de peles de titânio, cuja "produção é mitificada": um "fetiche forma-mercadoria em grande escala", nos termos do autor. ${ }^{88}$

A arquitetura "mais fenomênica do que literal", como a da poética do evanescente, que coloca em crise a dialética entre a tectônica (a estrutura, ou literal) e a pele (a imagem, ou superfície), defendida por Hal Foster (que segue a linhagem da tradição dominante da arquitetura moderna e de certa arquitetura brutalista contemporânea) não neutraliza, segundo Wisnik, o poder de negatividade da forma, até porque - pode-se supor, reforçando sua posição - sempre haverá alguma tensão, ainda que residual, entre a materialidade da forma e a imaterialidade da névoa. De todo modo, é preciso distinguir o sentimento do sublime, vivido pelo fruidor, em face de The weather project de Olafur Eliasson; ou o sentimento do sublime tecnológico, frente ao Blur Building de Diller + Scofidio; ou ainda, o "páthos de suspensão das faculdades", perante a plataforma de Sejima e Nishizawa; da distração tecnossublime light da sociedade do espetáculo. É preciso contrapor, em outros termos, uma efetuação estética disruptiva, situada entre a arte e a arquitetura, que opera como índice de alteridade, do efeitismo tecnológico, pirotécnico e decorativo, do eletroentretenimento, que apenas reafirma a realidade existente.

As formas da poética do nublamento são, portanto, "espaços de expectância e indefinição", que se opõem tanto ao espaço tecnocrático fundado na "ordem e eficiência" dos edifícios corporativos, sejam modernos ou contemporâneos, quanto ao espaço mais "abstrato e incomensurável” das nuvens da internet, próprias do "capitalismo globalizado, virtualizado" ${ }^{89}$ Essa arte/arquitetura da indetermina-

\footnotetext{
${ }^{88}$ Ibid., p. I52.

${ }^{89}$ Ibid., p. 21; I29; 223.
} 
ção - assim como os terrenos vagos ou os "lotes mortos” ainda encontráveis nas cidades contemporâneas - são "reservatórios de possibilidades de uso [ainda] não confinados pelos instrumentos do poder e pela razão abstrata"..$^{\circ \circ}$

Possivelmente essas rápidas considerações não fazem jus às nuances de Dentro do nevoeiro, mas se espera ao menos que elas tenham mostrado que esse é um livro que interpela prazerosamente o leitor, forçando seu pensamento para além do já sabido. Como ele ativa sua imaginação acionando a sirene de suas analogias, o que foi dito acima não traduz com exatidão a letra deste livro de prosa clara e urdidura rara, que se constituiu, desde seu lançamento, como referência obrigatória para a reflexão crítica sobre as práticas cruzadas da arte e da arquitetura no capitalismo digital-financeiro. Guilherme Wisnik não apenas evidencia a existência de formas artísticas e arquitetônicas de resistência, mas as toma como sintoma do drama vivido pela percepção em nossa época de estetização generalizada: "Enfim, o que está acontecendo com as imagens?”. ${ }^{11}$

Na poética do nublamento, na qual o efeito fenomênico triunfa sobre o literal, há a instauração de uma zona de indeterminação que pode ser aproximada do jogo que combina presença e ausência, o qual nos remete como vimos, à noção de figurabilidade, em Lyotard: "existe o desejo na medida em que o presente está

${ }^{90}$ Ibid., p. 129. É possível conjecturar se as noções de terrain vague ou "lote morto" - como os que foram ocupados pelo artista Gordon Matta-Clark, em Nova York, nos anos 1970 - ou seja, de espaços intersticiais ou vacúolos urbanos, de índole indefinida e metamórfica, e, portanto, de difícil representação, não poderiam ser aproximadas tanto das noções de "plataforma" ou "estação", caracterizadas pelo crítico e curador Nicolas Bourriaud, como "espaços de gestação de novos modos de vida"; quanto da noção de "heterotopia", entendida por Michel Foucault, como "contraposicionamentos em lugares reais"; ou seja, como "lugares que paradoxalmente estariam fora de todos os lugares", mas que encontraríamos no interior de espaços sociais já existentes. Cf. WISNIK, Guilherme. 20I8, p. I29; BOURRIAUD, Nicolas. Estética relacional. São Paulo, Martins Fontes, 2009, p. 29; FOUCAULT, Michel. "Outros espaços". In: Ditos e escritos III: Estética: literatura e pintura, música e cinema. Rio de Janeiro, Forense Universitária, 20oI, p. 415. Afinal, os fruidores na Turbine Hall na Tate Modern, em Londres; no Museu de Arte Contemporânea do SANAA em Kanazawa; ou no pavilhão Blur Building de Diller+Scofidio na “Expo 2002", em Yverdon-les-Bains, não estariam habitando de outro modo o mundo existente, ainda que apenas por certo tempo, dando concretude a estas noçóes de Bourriaud e Foucault? Essa conjectura, no entanto, pode ser uma associação abusiva, alheia, portanto, à intenção do autor.

${ }^{91}$ BAUDRILLARD, Jean. Simulacros e simulação, p. IO5; $20 \mathrm{I}$. 
ausente a si mesmo, ou o ausente presente"; ${ }^{22}$ ou ainda, à sua estética da "presença imaterial”, concebida a partir de sua interpretação da "analítica do sublime” de Kant. ${ }^{93} \mathrm{~A}$ fruição das obras comentadas é um sentimento de assombro na espera, uma abertura fundamental para além de sua submissão ao paradigma comunicacional, haja vista que esses fruidores vivenciariam a experiência de uma linguagem que não comunica, ou antes, de uma "comunicação... sem comunicação", posto que esta não expressa o sujeito nem se refere ao objeto (ou referente). ${ }^{94}$ Seria pela translucidez ou bruxuleio das formas arquitetônicas, que essas se insurgiriam contra a imoderação da beleza (ao sublime imanente ou digital). Na forma da presença imaterial, esta arte/arquitetura, ao preservar um nível de opacidade, abriria um campo de indeterminação em relação ao devir, subtraindo-se à comunicação corriqueira e à imagem hegemônica que reforçam a realidade dada.

$9^{2}$ LYOTARD, Jean-François. Por que filosofar? São Paulo, Parábola, 2013, p. 6I.

${ }^{93}$ LYOTARD, Jean-François, 1989, p. 90.

${ }^{94}$ Lyotard, Jean-François. "Algo assim como: comunicação... sem comunicação”. In: Parente, André (Org.). Imagem-máquina: a era das tecnologias do virtual. Rio de Janeiro, Editora 34, 1993, p. 93. 


\section{Referências bibliográficas}

ADORNO, Theodor W. Teoria estética. Tradução Artur Mourão. Lisboa: Edições 70, 1982.

AGAMBEN, Giorgio. O que é contemporâneo? e outros ensaios. Tradução de Vinicius Nicastro Honesko. Chapecó: Argos, 20009.

BAUDRILLARD, Jean. Tela total, mito-ironias da era do virtual e da imagem. Tradução de Juremir Machado da Silva. $3^{\underline{a}}$ edição. Porto Alegre: Sulina, 2005. BOURRIAUD, Nicolas. Estética relacional. Tradução de Denise Bottmann. São Paulo: Martins Fontes, 2009.

BLANCHOT, Maurice. O espaço literário. Tradução de Álvaro Cabral. Rio de Janeiro: Rocco, 1987.

COSTA, Mario. Osublime tecnológico. Tradução de Dio Davi Macedo. São Paulo: Experimento, 1995 .

DA VINCI, Leonardo. Tratado de pintura. Tradução de Angel González Garcia. $7^{\text {a }}$. Edição. Madri: Akal, 20 oro.

DELEUZE, Gilles. "Post-scriptum sobre as sociedades de controle". In: Conversações: 1972-19go. Tradução de Peter Pál Pelbart. São Paulo: Editora 34, 1992.

DIDI-HUBERMAN, Georges. O que vemos, o que nos olha. Tradução de Paulo Neves. São Paulo: Editora 34, 1998.

FAVARETTO, Celso. A invenção de Hélio Oiticica. São Paulo: Edusp, 1992.

FOSTER, Hal. O complexo arte-arquitetura. Tradução de Célia Euvaldo. São Paulo: Cosac \& Naify, 2015.

FOUCAULT, Michel. "Outros espaços”. In: Ditos e escritos III: Estética: literatura e pintura, música e cinema. Tradução de Inês Autran Dourado Barbosa. Rio de Janeiro: Forense Universitária, 20oI.

GILPIN, William. Essay on prints. Londres: Creative Media Partners, 2019. HANSEN, João Adolfo; "Pós-moderno \& Cultura". In: CHALUB, Samira. Pós-moderno: semiótica, cultura, psicanálise, literatura, artes plásticas. Rio de Janeiro: Imago, 1994.

KANT, Immanuel. Crítica da faculdade do juizo. Tradução de Valerio Rohden e Antonio Marques. Rio de Janeiro: Forense Universitária, 1993.

LIPOVETSKY, Gilles \& SEBASTIEN, Charles. Os tempos hipermodernos. Tradução de Mário Vitela. São Paulo: Barcarolla, 2004. 
LYOTARD, Jean-François. Por que filosofar? Tradução de Marcos Marcionilo. São Paulo: Parábola, 2013. . L'assassinat de l'experiénce par la peinture: Jacques Monory. Pandin: Le Castor Astral, 1984.

. Opós-moderno. Tradução de Ricardo Corrêa Barbosa. Rio de Janeiro: José Olympio, 1984.

. O inumano: consideraçôes sobre o tempo. Tradução de Ana Cristina Seabra e Elisabete Alexandre. Lisboa: Estampa, 1989. 1987. . Que peindre?: Adami, Arakawa e Buren. Paris: Éditions de la Différence,

PARENTE, André. (Org.). Imagem-máquina: a era das tecnologias do virtual. Tradução de Eugênio Luz et al. Rio de Janeiro: Editora 34, 1993. WISNIK, Guilherme. Dentro do nevoeiro. São Paulo: Ubu/Fapesp, 2018. . Estado crítico: à deriva nas cidades. São Paulo: Publifolha, 2009. \& Julio Mariutti. Espaço em obra: cidade, arte, arquitetura. São Paulo:

Edições SESC, 2018.

Resumo: Este artigo trata da convergência entre arte e arquitetura em uma poética dos materiais. Partindo da reflexão de "Dentro do nevoeiro" (Ubu, 20I8), de Guilherme Wisnik, investigamos em que medida certa arte e arquitetura ainda podem promover o sentimento de assombro em um mundo caracterizado pela dimensão global do espetáculo midiático e da tecnociência. É na poética do nublamento que localizamos formas residuais e emergentes de resistência à arte e arquitetura hegemônicas no capitalismo neoliberal, tais como as fotografias de Michael We-
Abstract: This article is about the convergence between art and architecture in a poetics of materials. Starting from the reflection of "Dentro do nevoeiro" (Ubu, 20I8), by Guilherme Wisnik, we investigate to what extent certain art and architecture can still promote a sense of amazement in a world characterized by the global dimension of media spectacle and technoscience. It is in the poetics of clouding that we locate residual and emerging forms of resistance to hegemonic art and architecture in neoliberal capitalism, such as the photographs by $\mathrm{Mi}$ - 
sely; as instalações de Olafur Eliasson; e chael Wesely; the installations by Olaas construções do escritório SANAA de fur Eliasson; and the buildings of KaKazuyo Sejima e Ryue Nishizawa; e do zuyo Sejima and Ryue Nishizawa's SAescritório Diller + Scofidio. É na forma NAA office; and Diller + Scofidio ofda presença imaterial da névoa que as fice. It is in the form of the immateobras destes artistas e arquitetos abrem rial presence of mist that the works of um campo de indeterminação em rela- these artists and architects open up a ção ao devir, na medida em que elas se opóem à comunicação corriqueira e às imagens hegemônicas que apenas reforçam a realidade existente.

Palavras-Chave: arte; arquitetura; contemporâneo; sublime; imaterial; resistência. field of indetermination in relation to becoming, insofar as they are opposed to the usual communication and hegemonic images that only reinforce the existing reality.

KEYWORDS: art; architecture; contemporary; sublime; immaterial; resistance. 